\title{
Review on the research progress of modified recycled concrete
}

\author{
Yihong,Wang ${ }^{1, a}$, Tao,Zhang ${ }^{1, b}$ and Jiawei Chen ${ }^{1, c, *}$ \\ ${ }^{1}$ College of Civil Engineering, Zhengzhou University, 100 Science Avenue, \\ High-tech Zone, Zhengzhou City, Henan Province, China \\ awangyihong_tumu@163.com, b961480006@qq.com, c857173053@qq.com
}

Keywords: recycled concrete; recycled coarse; modification methods; review of research.

Abstract. Nowadays, more and more waste construction waste is abandoned in China, which makes the problem of environmental protection especially prominent. The reuse of waste concrete not only helps to solve the problem of landfill, but also contributes to sustainable development of resources. However, due to some defects of Recycled Aggregate(RA), such as large water absorption rate, many microcracks and old mortar on its surface, which lead to the utilization rate of recycled concrete is relatively low. The compressive and tensile properties of Recycled Concrete(RC) are lower than ordinary concrete. A large number of scholars have modified RC to improve the defects of recycled concrete. This paper reviews the modification of the recycled concrete aggregate and adding admixture modification. And it raises questions and reasonable opinions, which provide scientific basis and references for further research in the field of modified concrete.

\section{Introduction}

The development of the construction industry consumes a lot of resources. A large amount of construction waste will be abandoned after the use of the building is over, which will have a huge impact on the sustainable development of the environment. If China produces about 40 million tons of construction waste every year, 34 percent of which is concrete, the resulting waste concrete will be 13.6 million tons. RC means to put the waste concrete after cleaning, crushing, grading, and cooperate with each other by certain proportion the "Recycled Coarse Aggregate(RCA) and Recycled Fine Aggregate(RFA)" as the preparation of some or all of the aggregate concrete [1-2]. (refer with: Fig. 1). However, Using RA in concrete preserves the environment by reducing the need for opening new aggregate quarries and decreases the amount of construction waste that goes into landfill. But, the physical and mechanical properties of RC are unstable because of natural defects of RA. Compared with Original Aggregate(OA), the RA has many defects, such as large water absorption rate, high porosity, crushing process there may be cracks, and poor durability factor. Many studies have shown that when the replacement rate of coarse aggregate is $30 \%$, the compressive strength reaches the maximum, then decreases with the increase of the substitution rate of coarse aggregate, but the overall mechanical performance is lower than that of ordinary concrete. In order to solve the above problems, Many researchers have done a lot of research. The mechanical properties and working performance of RC are enhanced by different modification methods. So that it can be applied to the structure. This paper introduces the modification of RC at home and abroad. The main points are: on the one hand, the RCA itself is modified. On the other hand, just add admixtures to the concrete. Next, according to the latest research results, each modification method is classified and discussed in detail. 


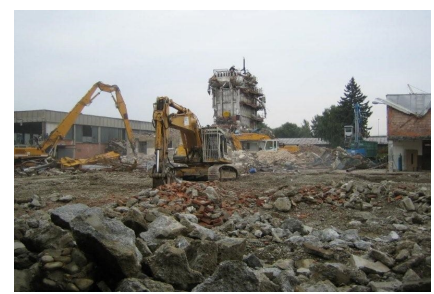

(a) Separation

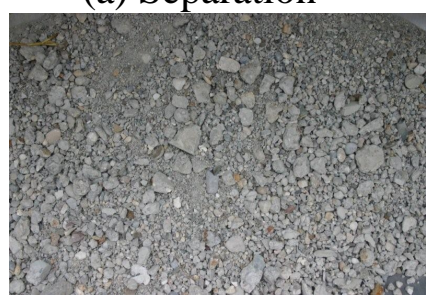

(d) Screening

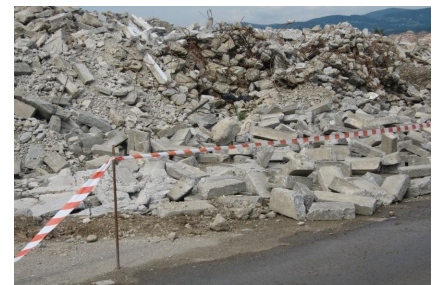

(b) Abandoned concrete

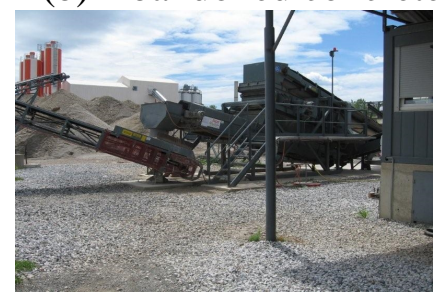

(e) Cleaning

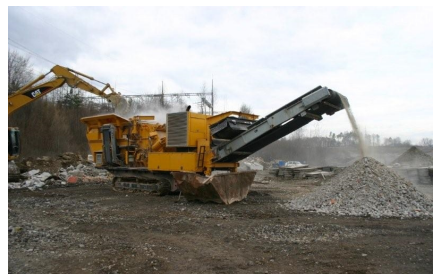

(c) Broken

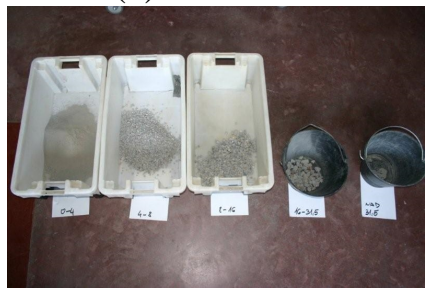

(f) RFA and RCA

Fig. 1 RA processing and production process

\section{Modification of RCA}

Reduce water absorption rate. the pored volume content of natural rock is very low, the water absorption rate of OA is very small. However, for the RCA, the composition contains about $30 \%$ of the hardened cement mortar (the porosity of cement mortar is large and the water absorption rate is high). combined with concrete block in the process of collapse, crushing due to the damage accumulation within a large number of microcracks, these factors make the porosity of the recycled aggregate content increases, so that the water absorption and water absorption rate increased. The amount of water used for the mix of recycled aggregate concrete is increased, and the concrete slump decreases in the process of mixing, which leads to the decline of the mechanical properties of RCA [3].

In order to reduce the water absorption rate of RCA, Chen D [4] used silicone water repellent to reduce the water absorption rate of coarse aggregate. Its main components are sodium methyl silicate and high-boiling silica sodium, which is a small molecular water-soluble mixture that produces sodium methyl silicate under the action of carbon dioxide and water in the air, and then further condenses into a network of silicone resin waterproof membrane. It is a hydrophobic material, and has strong penetration, can penetrate the certain depth of recycled coarse aggregate surface, made of recycled coarse aggregate surface and the contact angle of water increases, or to block of part of the porosity, and lower water absorption.

For the defects of large porosity and high water absorption rate of RCA, most physical modification is made by filling the hydrophobic material or filling the cracks so that the water molecules cannot be absorbed. Zhu Y and KOU [5,6] improved the RCA by using silane and PVA, the experimental results showed that both can improve the RC compressive strength. However, due to the hydrophobicity of silane, the interface bonding strength between the recycled concrete aggregate surface and the cement paste is poor.

Improve microfracture. The RCA not only has a large water absorption rate, but also produces more microcracks in the process of coarse aggregate production. Microcrack is one of the main reasons for the performance degradation of coarse aggregate. Studies [7] have found that recycled concrete fracture surface also have more recycled coarse aggregate is split, the destruction of the recycled concrete not only show the recycled coarse aggregate and cement paste interfacial bonding between damage, also show the more recycled coarse aggregate itself fracture damage, this is different from fracturing situation of ordinary concrete.

In order to improve the shortcomings of microcracks, Wang $\mathbf{J}[8]$ found that polyvinyl alcohol can infiltrate into the cement base capillary and form crystallization, and formed dense crystals when the water expands. At the same time, the slurry itself has a good bond with the concrete, and the filling effect of the slurry is enhanced, and the porosity of the surface mortar is reduced. Cohesive action can 
reinforce the loose and fragile mortar and improve the apparent characteristic of RCA, and improve the compressive strength of concrete test block.

Liu X [9] use three different proportions of pure water slurry, cement slurry, and silica powder mixed with silica powder to improve their working performance. The discovery of the chemistry modification, the size filled with the cracks in the surface of the recycled bone, reduced the porosity rate, the surface density of the recycled bone, the increased density of the aggregate, and improved the transition interface between the aggregate and the mortar. Compared with the three modified methods, the mechanical properties of the RCA were obviously improved by the addition of silica powder.

Remove old mortar on the surface of RCA. Although microcracks affect strength of concrete, But more and more studies have shown that the interfacial transition zone is the weakest link in concrete. The damage is usually started by the interface transition zone, and then the cracks extend and penetrate further, resulting in the destruction of the entire concrete block. However, for RCA, the interface transition zone is more complex and the influencing factors are more [10,13]. Leite, Monteiro and Le [14,15] found that in the RC system, the old mortar will reconstitute the interface transition zone with the new mortar. (refer with: Fig. 2).

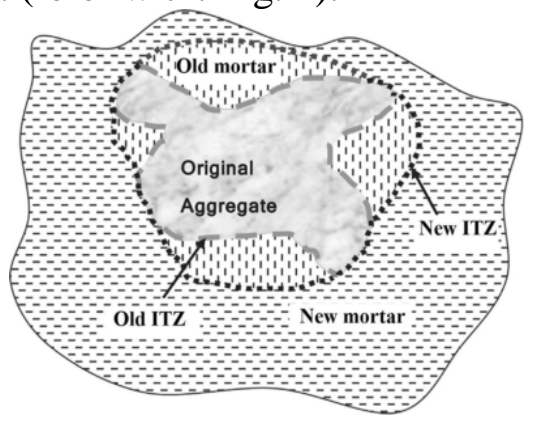

Fig. 2 Schematic of old and new ITZ in RCA concrete-adapted

Shen A [16] used polymer impregnated modification; It is found that the modification of polymer emulsion to concrete is to improve the performance of concrete by forming a membrane with high bond strength between cement slurry and aggregate.

Recycled concrete aggregate surface there are a lot of old mortar. Chen D [4] discoveries such as take a suitable amount of hydrochloric acid, the concentration of diluted to 3\%, the RCA into the mixture solution in $1 \mathrm{~h}$ after immersing, remove and dry. Measure its basic properties. It is proved that the modification of hydrochloric acid can remove the old mortar on the surface. This is because hydrochloric acid reacts with the hydration product $\mathrm{Ca}(\mathrm{OH})_{2}$ in the cement mortar on the surface of recycled coarse aggregate to destroy and improve the surface of recycled coarse aggregate particles, thus improving the performance of RCA. Moreover, Wang J [8] found that the improvement of the surface of the RCA surface with hydrochloric acid was better than that of oxalic acid, waterproof mortar and polyvinyl alcohol.

\section{Add admixture in RC}

Mixed with Nano-SiO2, fly ash, silica powder active material. Adding different active substances to RC can improve the defects of recycled concrete and enhance other properties of recycled concrete. At present, $\mathrm{Nano}-\mathrm{SiO}_{2}$, fly ash, silica powder are the main additives and active substances due to which are more effective.

With Nano- $\mathrm{SiO}_{2}$ solution immersion of recycled coarse aggregate, the $\mathrm{Nano}-\mathrm{SiO}_{2}$ as $\mathrm{Ca}(\mathrm{OH})_{2}$ in the old cement reaction generated $\mathrm{C}-\mathrm{S}-\mathrm{H}$ gel to fill in the recycled coarse aggregate pore and micro cracks, so as to improve the compactness and strength of the recycled coarse aggregate, achieve the goal of RCA modified. Fan Y [17] confirmed that the doping of $\mathrm{Nano}_{-} \mathrm{SiO}_{2}$ has certain effect on the modification of RC. Because Nano- $\mathrm{SiO}_{2}$ particle size small, and with strong volcanic activity, micro aggregate filling effect and crystal nucleus effect, after mixed with suitable amount of $\mathrm{Nano}_{-} \mathrm{SiO}_{2}$ can 
make the concrete internal structure is more compact, can effectively increase the strength and durability of concrete, to meet the requirements of the concrete engineering.

Compared with Nano-SiO 2 . The main components of silica fume include silica $\left(\mathrm{SiO}_{2}\right)$, sodium oxide $\left(\mathrm{NaO}_{2}\right)$, magnesium oxide $(\mathrm{MgO})$, and $\mathrm{CaO}$. These components can react with hydrated calcium hydroxide in cement to produce a large amount of hydration salts. These components can react with hydrated calcium hydroxide in cement to produce a large amount of hydration salts. Improved the fine structure of concrete. At the same time, Wang S [18] found that the mixed with silica fume, the blending with micro aggregate effect, filling the pores and cracks of recycled aggregates in concrete, lower porosity, improve the microstructure, so as to improve the ability to resist chloride ion penetration of $\mathrm{RC}$, the durability of the concrete.

Adding fly ash to the RCA can improve the hydration condition of cement, refine the pore diameter of $\mathrm{RC}$, and improve the concrete interface transition zone. The modification of fly ash is mainly through the formation of high adhesion film between cement slurry and aggregates, and the porosity in the mortar is blocked [19]. Chen W [20] showed that the compressive strength of RC decreased with the increase of fly ash content, and the strength reached the maximum when the fly ash content was $10 \%$. The splitting tensile strength decreases with the increase of fly ash content. The elastic modulus of modified RC is lower than that of ordinary concrete, and the degree of reduction is related to the compressive strength and water-cement ratio. But instead of fly ash cement and concrete in the gel decreases, when dosage of fly ash exceeds $10 \%$, the strength of the recycled concrete began to decline, shows that the modification effects of fly ash has its limits. Jiang $\mathbf{J}$ [21] also showed that the addition of fly ash and silica fume can improve the compressive strength of $\mathrm{RC}$, but the effect is not obvious.

Mixed with steel fiber, polypropylene fiber, rubber particle admixture. Adding steel fiber to the RC can enhance the toughening effect and transition zone boundary of the recycled concrete. There are many pores in the aggregate of recycled concrete, which easily leads to stress concentration, but because of the addition of steel fiber, can block crack propagation of crack resistance effect, at the same time, the technical specifications of the recycled concrete has different degree of ascension. Jiang J [21] found that adding steel fiber can effectively improve strength of RC. Gao D studies [22,23] indicated that the compressive strength of the steel fiber regenerated concrete cube is slightly lower than that of the corresponding steel fiber natural concrete. The effect of steel fiber on the compressive strength of RC cube is obvious. Yang R [24] tested the mechanical properties of steel fiber recycled concrete and found that the addition of steel fibers has significantly improved the anti-splitting ability of the RC, but the strength of the tensile strength has not improved.

After adding polypropylene fiber can be evenly distributed in the matrix in the concrete, the constraints of the matrix concrete, and concrete to share the load, improve the modified recycled RC compressive strength and tensile strength. Jiang J [21] showed that adding polypropylene fiber can effectively improve the compressive strength of RC. Yang Y [25] found that the enhancement effect of fiber on the tensile strength of RC was significantly higher than that of fiber on the compressive strength of $\mathrm{RC}$. Wu $\mathrm{J}$ [26] research shows that the change of the polypropylene fiber content, the larger impact on the strength of the polypropylene fiber RC, especially the impact on the splitting tensile strength, when the fiber content is $1.5 \mathrm{~kg} / \mathrm{m}^{3}$, splitting tensile strength increased by $25.9 \%$. However, after the fiber content exceeds $1.2 \mathrm{~kg} / \mathrm{m}^{3}$, the strength growth rate of polypropylene fiber RC slows down.

The effect of adding rubber particles to $\mathrm{RC}$ is the same as that of ordinary concrete. because the surface of the waste rubber particles is hydrophobic, and the inorganic cementing material is not infiltrated, the interface of the concrete matrix is relatively weak, which leads to the decrease of concrete tensile strength [27]. On the other hand, due to the elastic material of scrap rubber, the stress concentration of the splitting surface is alleviated to some extent, which leads to the improvement of concrete tensile strength. The addition of rubber particles in concrete can improve the ductility, crack resistance, anti-seepage, antifreeze and shock absorption of RC. 


\section{Problems and Improvements}

(1) When the modification of recycled concrete is improved, it is necessary to start from its mechanism and not take it for granted to increase or take a try. Grasp the main factors that affect the performance of RC. For example, it is modified by water repellent, How much has the modified effect improved? What about the price ratio? The researchers did not conduct a comparative experiment.

(2) A large number of researchers are not clear about the purpose of modifying recycled concrete. Improvements should be made according to a specific performance. They need to put together a complete system. And the research lacks depth and breadth.

(3)There are a lot of arguments for modified recycled concrete before it is applied to the engineering structure.

\section{Conclusions}

For our country to establish a resource-saving, environment-friendly country, the reuse of concrete can not only save resources, but also protect the environment. The research on recycled concrete should be strengthened. From the microstructure modification, the macroscopic effect can be changed from the mechanism, so that the defect can be solved well.

(1)The development and application of recycled concrete technology, not only can fundamentally solve the problem of waste concrete way out, and reduce the environmental pollution caused by waste concrete, also can save the natural aggregate resources, decrease of nature. However, since the overall performance of $\mathrm{RC}$ is lower than that of ordinary concrete, the research on its modification is the primary task.

(2)According to the current domestic and foreign research data show that the RCA than normal concrete has greater discreteness and more complex interface transition zone, its itself exists many defects. In order to improve the damage performance of modified RCA, it is necessary to understand its failure mechanism and internal mechanism. Different modification measures were found according to different demands and destruction patterns.

(3)In the future, the RC should be applied to the structure, and it should be considered in the process of modification, such as the cost problem and the degree of enhancement. Construction complexity problem, etc.

\section{Acknowledgments}

The authors would like to thank the Key Scientific Research Projects of Henan Province (18A560022) and Undergraduate Innovation and Entrepreneurship Program (32650007). Special thanks to Xinzhe Wang for his participation in this paper.

\section{References}

[1] Du T, Li H, Qin Y and Zhong S: Concrete. (2002), p. 49-50

[2] Shi X, Wang Q, Qiu C and Zhao X: Journal of Sichuan University(Engineering Science Edition). Vol. 42-S1 (2010), p.170-176

[3] Liu G and Xiong F: Chinese Journal of Underground Space and Engineering. Vol. 13-04 (2017), p. $970-973$

[4] Chen D, Yuan W and Liu H: New Building Materials. Vol. 36-02 (2009), p. 20-23

[5] KOU S C, POON C S: Cement and Concrete Composites. Vol. 32-8 (2010), p. 649-654

[6] Zhu Y, Xu P: Concrete. Vol. 03-025 (2015), p.93-101

[7] Jiang L, Zhu F, Zhou D, Zhu Z, Wang J and Zheng C: Bulletin of the Chinese Ceramic Society. Vol. 34-07 (2015), p. 2007-2012

[8] Wang J, Geng O and Li F: Journal of Architecture and Civil Engineering. Vol. 33-02 (2016), p. 91-97 
[9] Liu X, Xing Z, Meng G and Zhang Y: Shanxi Architecture. Vol. 43-30 (2017), p. 109-110

[10] Chen Y, Sun Z and Xiao J: Concrete. (2004), p. 10-13.

[11] Li W, Long C, Luo Z, Huang Z, Long B and Ren J: Journal of Architecture and Civil Engineering. Vol. 33-06 (2016), p. 60-72.

[12] Chen M, Zhong J, Wu S, zhu J and Wang D: Highway. (2011), p. 198-201

[13] Shui Z, Pan Z and Zhu W: Journal of Wuhan University of Technology. Vol. 25-12 (2003), p. 99-102

[14] Leite, M.B, Monteiro, P.J.M. Cem: Concr. Res. Vol. 81 (2016), p. 38-48

[15] Le. T, Le Saout. G, Garcia-Diaz. E. Betrancourt. D, Rémond. S: Constr. Build. Mater. Vol. 141 (2017), p. 479-490

[16] Shen A, Li Z and Wang X: Concrete. (2001), p. 40-42

[17] Fan Y, Niu H and Zhang X: Concrete. 2017, p. 92-95

[18] Wang S, Yu Y, Zhang B, Zhao K and Fan Y: Concrete. (2011), p. 53-55

[19] Rawaz Kurda, Jorge de Brito and José D. Silvestre: Construction and Building Materials. Vol. 157 (2017), p. 554-572

[20] Chen W, Xiao J and Fu J: Engineering and Construction. Vol. 29-05 (2015), p. 651-654

[21] Jiang J and Xu H: Concrete. (2014), p. 87-89

[22] Gao D, Lou Z and Wang Z. Journal of Zhengzhou University(Engineering Science). Vol. 28-02 (2007), p. 5-10

[23] Zhang L, Gao D and Zhu H: Journal of North China Water Conservancy and Hydropower University. Vol. 34-01 (2013), p. 27-31

[24] Yang R, Yin Z and Xiao H: Concrete. Vol. 195-1 (2006), p. 27-42

[25] Yang Y and Wang J: Journal of Liaoning Technical University (Natural Science). Vol.32-12 (2013), p. 1670-1672

[26] Wu J, Ma S, Tang Z and Cao T: Highway Engineering. (2007), p. 110-112

[27] Zeng H, Wu Y and Long X: Guangdong Architecture Civil Engineering. Vol. 21-03 (2014), p. $36-38$ 